\title{
The assessment of quality of life in peripheral urban areas in Lithuania
}

\author{
Marija Burinskiené $\dot{1}^{1}$ Vitalija Rudzkiené $\dot{2}^{2}$ Dovilè Lazauskaite் ${ }^{3}$ \\ ${ }^{1}$ Department of Urban Engineering of Vilnius Gediminas Technical University, Vilnius, Lithuania \\ ${ }^{2}$ Institute of Economics and Business of Mykolas Romeris University, Vilnius, Lithuania \\ ${ }^{3}$ Research Institute of Territorial Planning, acronyms acceptable, Vilnius, Lithuania
}

\section{Email address:}

Marija.burinskiene@vgtu.lt (M. Burinskienè),vital@mruni.eu (V. Rudzkienė), dovile.lazauskaite@vgtu.lt (D. Lazauskaitè)

\section{To cite this article:}

Marija Burinskienè, Vitalija Rudzkienė, Dovilè Lazauskaitè. The Assessment of Quality of Life in Sub Peripheral Urban Areas in Lithuania. Social Sciences. Vol. 2, No. 6, 2013, pp. 222-230. doi: 10.11648/j.ss.20130206.17

\begin{abstract}
After political changes and transformations, many large cities in Eastern Europe in the last decade are confronted with decline in population, privatization patterns, deterioration, raised the land prices, lower life satisfaction. In the point of macro level view this process is estimating as a controversial spatial flow. It changes the traditional urban structures and affects the successful social and economic development in cities and actually influences competitiveness in wider pan European scale. Future Orientation for Cities project (FOCI) implemented by the European Observation Network for Territorial Development and Cohesion (ESPON) 2013 Program, provided comparable information on territorial dynamics of European regions and main drivers of current urban sprawl. Quality of life is described as one of the main drivers of urban sprawl. In micro level it captures the decisions of individual actors in the urban system. The individuals construct a distinctive quality of life model. Such apparently multi-dimensional attitude encourages authors in finding ways how to establish objective criteria for a subjective assessment of the quality of life of city centre and peripheral community members. On the basis of FOCI project results and social research carried out in in the capital of Lithuania, the authors, regarding data obtained conducting a representative survey among permanent residents in Vilnius city, have made an attempt to assess the peripheral areas in Vilnius and to identify the indexes having an impact on a subjective evaluation of the quality of life.
\end{abstract}

Keywords: Sub Peripheral Urban Area, Subjective or Objective Indexes, Quality of Life

\section{Introduction}

The Future Orientation for Cities project (FOCI) implemented by the European Observation Network for Territorial Development and Cohesion (ESPON) 2013 Programme, provided comparable information on territorial dynamics of European regions. On the basis of the project analysis results, is confirmed the fact, that not all countries and regions in Europe are at the same stage of the urbanization cycle and the differences in urbanism in the European Union are increasing. This is felt the most in post - socialist countries. After political changes and transformations, many large cities in Eastern Europe in the last decade are confronted with decline in population, privatization patterns, deterioration, raised the land prices, lower life satisfaction. These elements have lead to increased suburbanization and sprawl. Authors of this paper are focusing on Lithuanian city suburbanization process and are using driving forces of urban sprawl new paradigms (quality of life) identified in FOCI project results to approach a strategy or model to fully develop sustainable development ideas in Lithuanian territorial planning.

Quality of life studies are attracting urban planners and policy makers because of its usefulness for formulating and implementing public policies, strategies and for evaluating and monitoring implemented public policies and strategies. Quality of life can be measured using subjective, objective indicators or by combining both. Quality of life research which is designed to facilitate urban planning and policy making should be measured using both subjective and objective indicators. Quality of life relates to description and assessment of the conditions of life of people in a certain country or region. Most of quality of life studies are at a regional and country level [10.12.15]. Macro level and meso 
level assessments are hiding spatial variation in quality of life that could prevail at micro level (periphery, district or city centre).

Consequently, to measure quality of life as an important driver of urban sprawl, and identify the main links for adaptation in urban planning a mixed method of data collection at multi-level (the districts of capital city of Lithuania) analysis is applied in this paper.

\section{Quality of Life}

\subsection{The Concept of Quality of Life in Urban Planning}

The quality of life can be investigated considering economic, social, psychological, medical etc. positions. Certainly, every academic subject uses a different approach to examining the construct of the quality of life [2] and applies the concept itself at individual, local community and public levels. Nearly 50 years ago, a conceptual idea of referring to social-economic research, which is a component of many-sided public development and welfare, as to investigation into the quality of life was formed in the U.S.A Scientific literature interprets the concept of the quality of life with respect to different criteria and combinations of various factors. However, the definitions of the quality of life most frequently embrace individual, public, emotional, social and physical well-being. From an urban point of view, the sustainable development of modern cities seeks for in-depth research on the quality of life, which is an integrated part of investigation into this particular field.

The quality of urban life can be accepted as the evaluation of life circumstances individually set by community members, whereas the fundamentals of the quality of life, as a social equivalent of environmental performance, are related to the benefit received from any economic activity. Thus, it can be concluded that residents will prefer a living place in the urban area if cities satisfy their expectations: an outstanding quality of life that is admitted individually, i.e. a sustainable city [1].

Striving for the quality of urban life means the ability to open up an opportunity to implement individual natural and legal rights and stay personally satisfied with things available in different areas of life. The society itself or simply individuals construct a distinctive quality of life model that can be acceptable to them only. Such apparently multi-dimensional attitude encourages researchers in finding ways of how to more accurately analyse, measure and evaluate the situation, i.e. to establish objective criteria for a subjective assessment of the quality of life of community members, the criteria should reflect the conception of the quality of life of the whole community. Research on the quality of life is often abstract, and evaluation using traditionally accepted indexes (for example, household assessment, living conditions estimates) more openly displays the condition of living standards in one or another country rather than the situation showing the quality of life itself. The previously shaped opinions suggest that economic growth based on increasing income has been a key tool for improving the quality of life. However, other factors can also have a crucial impact; a physical and natural urban environment as well as population health may influence a number of more vulnerable groups of the inhabitants.

As quality-of-life indexes may vary substantially, different countries present different lists of such indicators. According to data on research conducted by the real estate magazine International Living issued in the U.S.A., in 2010, Lithuania reached the $22^{\text {nd }}$ position considering the quality-of- life index. According to the information provided by the same magazine, Estonia achieved the $32^{\text {nd }}$ and Latvia - $40^{\text {th }}$ positions respectively. 194 countries were involved in the performed investigation. The authors of the research calculated the quality-of-life index referring to nine categories, including the cost of living, leisure and culture, economy, freedom, health state, infrastructure, risk and safety, climate. The annual World Report on social well-being is prepared by the United Nations Development Programme (UNDP) and counts Human Development Index (HDI) in 175 countries. Considering three basic components of human and social development (average life expectancy, adult literacy rate and combined gross enrolment ratio in primary, secondary and tertiary education, gross domestic product (GDP), Lithuania takes the $45^{\text {th }}$ position [16].

A comparison of the results of international evaluation systems providing quality-of-life indexes shows that the position attained by the State differs. This is due to a different application of the indexes that create systems for the quality of life and because of a lack of a common system.

Which is the real quality of life, and what is an objective evaluation of quality that can promote the development of sustainable cities? Hence, what has a real impact on the quality of life and what makes preconditions for improving the situation in the city; how can a subjective perception of the quality of life be reflected in an objective easily comprehensible form?

\subsection{Evaluation Methodology of the Quality of Life in Urban Planning}

In order to systemise the literature on drivers of urban sprawl the following dimensions have been considered: scale, demand and supply and domain [7]. Scale is dividing in three levels: macro (political and economic paradigms that shape the nature of the urban societies), meso (where much of the discourse about the causes of urban sprawl can be found) and micro level (captures the decisions of individual actors in the urban system). The drivers of urban sprawl focus on the demand, but the supply side may be more important than demand alone [6]. Domain includes society, economy, governance, transport and land. This categorisation relates to the ESPON projects on polycentricism and economic change [9] and to the basic determinant blocks of regional competitive performance presented in FOCI project [8]. 


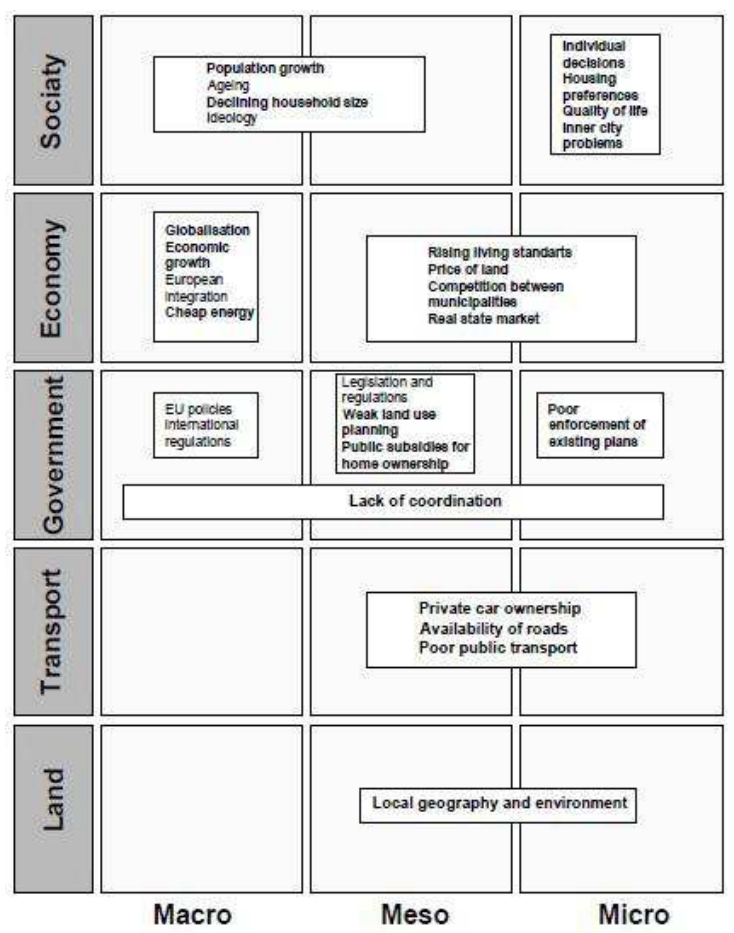

Figure 1. Main drivers of current urban sprawl in Europe [7].

Quality of life in Fig. 1 is one of the main factors relevant at micro level. The quality of life in urban planning can be accepted as the final result of a sustainable city and wider spatial development. Cities can influence many factors of quality of life: build and natural environment, mobility within the city, urban aesthetics, accessibility to services, et. How much this factor actually influences urban sprawl and how more precisely to assess it remains an open question.

Some studies of quality of life are conducted at national level, some at regional level, but very few are conducted at a lower scale like neighbourhood or sub-city level [17, 19].

However, attempts to assess the quality of life show that every person and/or society can devise a unique formula that will have an individual character and cover specific components and criteria for the quality of life.

\subsubsection{Subjective and Objective Indexes of Quality of Life}

The previous experience points to either only subjective or objective indexes used for evaluating the quality of life. The selection of the indexes used to be determined by a choice made by the researchers or by a possibility of conducting research on the quality of life. An objective evaluation of the quality of life is based on statistical data. The source of data on subjective indexes most frequently involves questionnaires and reports on investigations indicating the consciousness of urban dwellers concerning the quality of life and personal welfare of the population. Subjective measurements of the quality of life are usually expressed applying to the scale showing degrees from 'fully satisfied' to 'very dissatisfied'.

A share of GDP attached to a single person was the very first attempt to somehow assess the quality of life. Nevertheless, it has been noticed that this particular index cannot reflect subjective expectations and achievements in sustainable development. Therefore, the level of assessing the quality of life can contradict the reality. Moreover, this index is a commonly accepted macro-economic indicator. Thus, it should be emphasized that with reference to GDP, the development, progress and recession are the areas of general evaluation. To relate the measurement of the quality of life to the evaluation results of sustainable city development, the GDP index is still more complex to be applied for assessing the quality of life in a certain living area. In 1980, a transport studies group from the University of Westminster, United Kingdom, brought together experts and society members to identify the qualities of a civilized city and establish the indexes having an impact on forming the characteristics of economy, environment and the quality of life (Table 1).

Table 1. The qualities of the civilized city identified by the expert group formed by the transport studies group from the University of Westminster and the indexes forming the characteristics of economy, environment and the quality of life [4]

\begin{tabular}{|c|c|}
\hline Qualities of the civilized city & Indexes of economy, environment and the quality of life \\
\hline $\begin{array}{l}\text { a) decreasing crimes / increasing safety; } \\
\text { b) cleaner and more attractive environment; } \\
\text { c) satisfactory employment opportunities; } \\
\text { d) health of the population; } \\
\text { e) decreasing poverty; } \\
\text { f) improving living conditions; } \\
\text { g) high quality education system; } \\
\text { h) great availability of local services; } \\
\text { i) models for more sustainable consumption. }\end{array}$ & $\begin{array}{l}\text { Violent and non-violent crime, safety (traffic, personal), employment (unemployment rate), } \\
\text { remuneration (average weekly earnings), education (acquired background), health-state } \\
\text { (problems of the incidence of congestive heart failure and severe breathing), weather quality } \\
\text { (quality of local weather), noises (disturbances in the street and at home), accommodation } \\
\text { conditions (state, homelessness), transport (flows, traffic-jams, travel time variation, economic } \\
\text { viability (non-residential construction), sustainability (a rise in co, recycling), accessibility } \\
\text { (walking comfort and approachability, relative mode for travel time), travelling and activity } \\
\text { (travel with no car, time spent out of home), community (sense of belonging, local infrastructure } \\
\text { of spare time/rest). }\end{array}$ \\
\hline
\end{tabular}

The above table shows that the indexes evaluating the quality of life cover not only personal income, employment, physical and psychological health, social needs for education, rest and spare time but also surroundings and the built environment.
Eventually it is supposed that the evaluation of objective indexes only cannot convey the real quality of life [10]. On the other hand, subjective indexes cannot disclose the specificities of a physical environment and displace conditions for the place of residence [5]. Both evaluations, in terms of scientific research, in the context of spatial 
planning, encourage revealing the relationship between objective and subjective factors [11, 12].

An overview of scientific research reminds that the quality of life consists of an integrated assessment of subjective and objective indexes. Therefore, a conceptual model for measuring the quality of urban life, suggested by Rogerson (1999), covered the qualities of a physical urban environment, human characteristics (giving more weight) and personal experience (sense of welfare analysis) and was supplemented with establishing personal goals and expectations.

The physical urban environment meets every day needs and complies with the expectations of the population, which causes a high quality of life. Investigation into the quality of life in different localities (cities, regions, states) or communities reveals that the presently applied indexes also indicate a public attitude towards this issue. The indexes distinguishing personal features are used for establishing the distribution of resources so that to improve the quality of life, assess planning impacts and help with achieving the objectives. Thus, in the field of spatial planning, the evaluation of a general quality of urban life discloses two groups of indexes: the first one defines the surroundings and physical environment of the city, whereas the second depicts personal well-being and expectations of the population.

Although the great potential for relationship between indexes is noticed, the indicators that can be applied for preparing, implementing, monitoring and revising urban development projects, which should be a useful tool for scientific research, are still a minority [14]. The first attempt to design an index system showing the quality of life was made in the U.S.A [18].

Considering experience individually gained by one or another country to evaluate a general condition of the quality of life, a wide complex calculation and comparison of measures - Human Development Indexes, including Social Development Indicator, the Index of Sustainable Economic, Personal Savings Rate, Ecological Footprint, etc. can be observed.

These are relative measures quantitatively defining variations in the quality of life in terms of time and space. The measures are expressed in numbers and periodically refreshed so that to reflect quantitative changes in the researched quality of life among different countries. All indicators making indexes are GDP modifications made introducing modifications in national accounts in order to involve a higher number of determinants such as environmental degradation, natural capital depreciation, etc. [16].

Obviously, the index can assist in displaying tendencies towards the quality of life, i.e. indicate whether the quality of urban life is decreasing, increasing or remains stable. The tendencies can only be revealed under the circumstances of long-term index measurements: sustained statistics of the index must be provided. The longer the index has been calculated, the more precisely the development of the index and the quality of life reflecting progress can be forecasted. The process of making major strategic decisions important for the city and its agglomeration shows that this tool can be successfully used for setting the level of urban progress, establishing deviations and promoting the efficiency of implemented plans and programs [3]. On these grounds, promising priorities of spatial planning can be identified, as they allow estimating territorial differences in certain indexes thus offering measures for equalizing them [1].

Evidently, the index combines subjective and objective indicators for evaluating the quality of life and therefore becomes more precise involving a higher number of subjective indicators.

The analysis of quality-of-life indexes applied in Lithuania has revealed that, at the government level, the Department of Statistics to the Republic of Lithuania imparts statistical information on changes in the quality of life and collects and examines data considering 8 topics that define the quality of life at national and regional levels. The document investigates the level of the risk of poverty, severe material deprivation rate, the coefficient of income distribution, the level of housing deprivation, the proportion of persons living in households with very low work intensity, fixed term employment contracts, employed population at-risk-of-poverty, unemployment level, average life span expectancy, infant mortality rate, overall mortality rate, a share of the youth that left school early, a share of the population that acquired lower, middle or highest (primary, basic and secondary respectively) levels of education and the level of lifelong learning.

Apart from collecting statistical data, and having evaluated the situation that changes in GDP are not crucial factors in measuring social welfare, environmental and public sustainability and human prosperity, one more area of the quality of life - overall life satisfaction - has been added to the above mentioned 8 topics. In the meantime, statistical indicators has not been applied to this particular field; however, a questionnaire about overall life satisfaction, the assessment of the meaning of life and psychical health has been included in welfare investigation planned in 2013.

Thus, one of the major goals is finding a method for providing a subjective opinion with an objective form thus creating indexes having an impact on a general quality of life through variations in territory planning indicators. In such a case, the quality of life could be reached referring to a single index generalizing other quality-of-life indexes.

On the basis of social research carried out by Lithuanian company RAIT in the city of Vilnius, the authors of the article, regarding data [12] obtained conducting a representative survey among permanent residents in Vilnius city, have made an attempt to assess the neighbourhood areas in Vilnius and to identify the indexes having an impact on a subjective evaluation of the quality of life. Hence, while working out the added value of the index summarizing the objective quality of life indicators and a subjective position as well as the formation and application of the index, Vilnius Municipality has been chosen on the grounds it is the capital 
and biggest city of Lithuania and the centre of Vilnius district, region and municipality as well as has good spatial and social accessibility to a great abundance of research data taking into account a primary purpose of the population to move to the capital city.

\section{Evaluation of Districts in Vilnius}

\subsection{Establishing Subjective Quality-of-Life Indexes}

For the purpose of realizing subjective quality-of-life indexes in the city of Vilnius, the conducted research used data received via a representative sample taken by UAB RAIT in March 2005. 2575 permanent residents from 16 to 74 year old in Vilnius city were surveyed.

Fig. 2 shows the index 'The intentions of Vilnius residents to move to another place to live now or in a few years' time' was chosen as a general indicator reflecting the quality of life and expressed in percent.

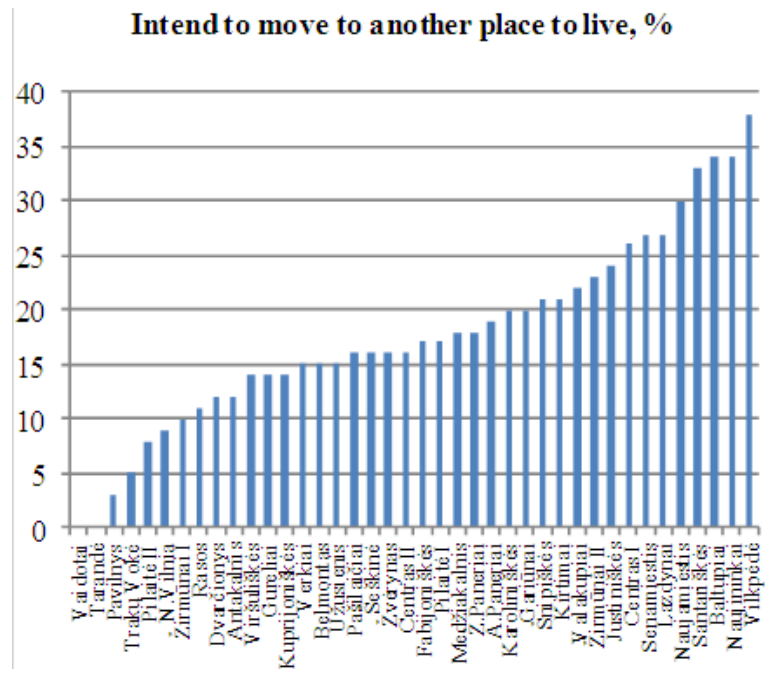

Figure 2. Vilnius neighborhoods arranged considering resident intentions to move to another place to live now or in a few years' time, \%.

Investigation into the relationship between the above introduced indexes measured in Vilnius districts with other measured variables (17 groups of variables in total) has disclosed that this particular index has a statistically significant correlation with some other indexes from the group 'Environmental assessment of the district and residential house'.

To predict a place of residence, a multiple regression model has been used

$$
Y=\beta_{0}+\beta_{1} X_{1}+\beta_{2} X_{2}+\ldots+\beta_{n} X_{n}+\varepsilon
$$

where: $\beta_{0}, \beta_{1}, \ldots, \beta_{n}$ - unknown constants, and $\varepsilon$ - random error.

The coefficients of the equation are defined applying the least square method from the equation

$$
\beta=\left(X^{\prime} X\right)^{-1} X^{\prime} Y
$$

For statistical analysis, SPSS software has been used.

To choose statistically significant variables, the 'forward selection' method of correlation analysis and regression analysis has been applied, i.e. the predictive variables are selected employing step by step technique introducing one variable into the equation.

The conducted analysis allowed identifying independent variables (perceivable) most accurately predicting a dependent variable (intention to move to another place to live):

1. Evaluation of the noise generated by transport in the yard - 'felt' (114);

2. Evaluation of air pollution in the residential environment considering neighbourhoods - 'heavy' (162).

Thus, the regression model can be expressed as

$$
y_{i}=b_{0}+b_{1} x_{1, i}+b_{2} x_{2, i}+e_{i} \quad i=1, \ldots, 40
$$

where: $Y$-intentions to move to another place to live, $x_{1}-$ feeling the noise generated by transport in the yard (perceived), $x_{2}$ - heavy air pollution in the residential environment (perceived).

Having calculated the coefficients of the equation, a multiple regression equation has been worked out:

$$
y=7,438+0,289 x_{1}+0,202 x_{2}+e .
$$

The determination coefficient of the equation $R^{2}=0,461, \quad R_{a d j}^{2}=0,432$.

$$
R_{a d j}^{2}=1-\frac{n-1}{n-k-1}+\left(1-R^{2}\right)
$$

The statistical significance of the coefficients used in the equation has been checked employing criterion $t$ :

$$
\begin{gathered}
H_{0}: \beta_{i}=0 \\
H_{A}: \text { at least one } \beta_{i} \neq 0
\end{gathered}
$$

To verify the hypothesis, an interval of coefficient reliability is made:

$$
b_{i}-t_{\alpha / 2,(n-k-1)} \sqrt{S_{e}^{2} C_{i i}} \leq B_{i} \leq b_{i}+t_{\alpha / 2,(n-k-1)} \sqrt{S_{e}^{2} C_{i i}} .
$$

The hypothesis is rejected if $|t|>t_{\alpha / 2,(n-k-1)}$.

Done calculations have disclosed the criteria of $t$ that are 3 , 49; 4,908 and 2,650 respectively. The zero hypothesis has been rejected, because the obtained observed levels of significance are higher than $0,05(0,001 ; 0,00002 ; 0,012$ respectively).

The multicollinearity of variables has been verified calculating the index of decreased dispersion:

$$
\operatorname{VIF}\left(\beta_{i}\right)=\frac{1}{1-R_{i}^{2}}
$$

It is required that most frequently $V I F<4$. In this case, the condition of $V I F=1$. and multicollinearity is satisfied. 
As the regression equation coefficients next to variables $x_{I}$ and $x_{2}$ are positive, it could be maintained that the intention of the residents to move to another place to live is influenced by the noise generated by transport in the yard and heavy air pollution in the residential environment. The higher are the numerical values of these indexes, the more likely residents are intended to move to other places to live.

\subsection{Establishing Indexes Objectively Influencing the Subjective Evaluation of the Quality of Life}

What measurable indicators are related to the perceivable variable 'Evaluation of the noise generated by transport in the yard - 'felt' (114).

Nois e genarat edby transportin the yard, 'felt', \%

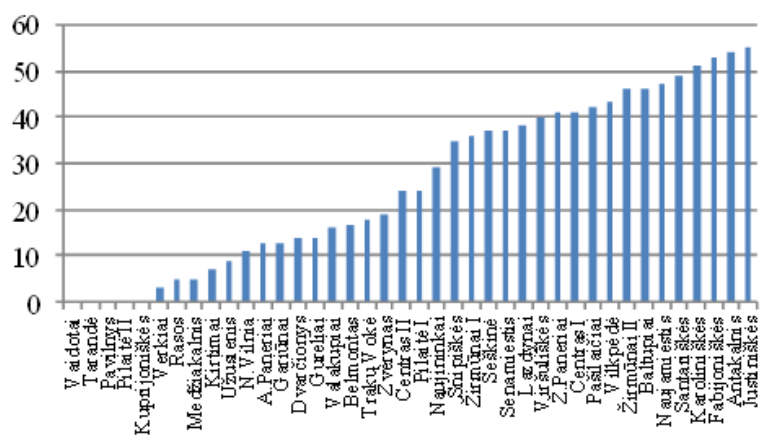

Figure 3. Vilnius districts arranged considering residents' awareness of the noise generated by transport in the yard ('feeling noise'), \%.

For analysing what measured indexes are related to residents' awareness of the noise generated by transport in the yard, a correlation-regression analysis of selected 13 measured variables $z_{i}, \quad i=1,13$ linked to noise has been conducted.

The regression equation has involved two independent variables: population density of the district $\mathrm{p} / \mathrm{ha}\left(5^{\text {th }}\right.$ variable $)$ and traffic flow during the peak hour (measured in 2000).

Thus, the regression model is:

$$
x_{1, i}=b_{0}+b_{1} z_{1, i}+b_{2} z_{2, i}+e_{i}, i=1, \ldots, 40,
$$

where: $x_{1}$ - feeling the noise generated by transport in the yard, $z_{1}$ - population density of the district, $\mathrm{p} / \mathrm{ha}, \mathrm{z}_{2}-$ traffic flow during the peak hour (year 2000).

Having calculated the coefficients of the equation, a multiple regression equation has been worked out:

$$
x_{1}=1,31+0,295 z_{1}+0,007 z_{2}+e .
$$

The determination coefficient of the equation $R^{2}=0,629, \quad R_{\text {adj }}^{2}=0,607$.

The coefficients of the equation are statistically significant

$\left(\rho_{\text {int } \text { ercept }}=0,075, \rho_{z 1}=0,00004, \rho_{z 2}=0,005\right.$, respectivel $\mathrm{y})$.

The multicollinearity of variables has been verified calculating the index of decreasing dispersion VIF. The value of both variables $V I F=1,284$ shows that the condition is satisfied.

Residents' awareness of the noise generated by transport in the yard is influenced by two indexes: population density of the district and traffic flow during the peak hour. The higher are these indexes, the stronger residents are exposed to the noise generated by transport.

How are the measured variables related to the perceivable variable 'Air pollution in the residential environment' 'heavy' (114).

\section{Air pollution in the residential environment - 'Heavy', \%}

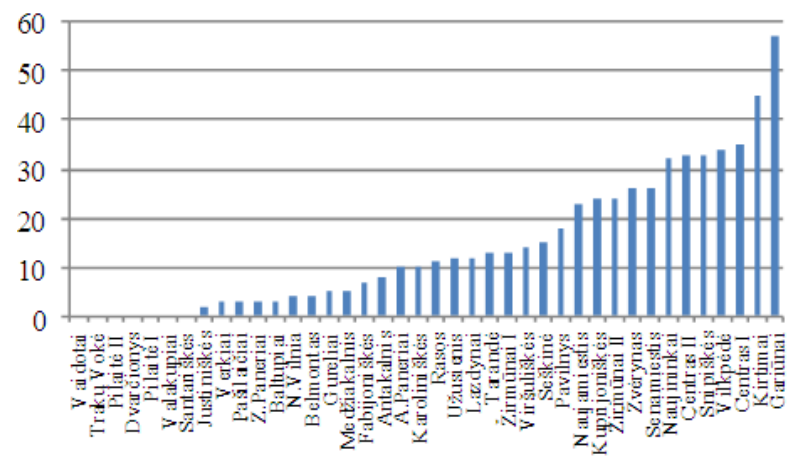

Figure 4. Vilnius neighborhoods arranged considering residents' awareness of air pollution in the residential environment ('Heavy', \%).

The conducted analysis has disclosed that, from 16 selected measured variables $p_{i}, \mathrm{i}=1,16$ related to air pollution in the residential environment, two independent variables 'distance to the city centre' (73) and 'density of streets' (11) can be included into the regression equation.

Thus, the regression model is:

$$
x_{2, i}=b_{0}+b_{1} v_{1, i}+b_{2} v_{2,1}+e_{i}, \quad, \quad i=1, \ldots, 40,
$$

where: $x_{2}$ - heavy pollution in the residential environment, $v_{1}$ - distance to the city centre, $\mathrm{km}, v_{2}$ - density of streets, $\mathrm{km} / \mathrm{km}^{2}$.

The regression equation is as follows:

$$
x_{1}=18,201-2,164 v_{1}+1,129 v_{2}+e .
$$

The determination coefficient of the equation $R^{2}=0,642, \quad R_{a d j}^{2}=0,613$.

The coefficients of the equation are statistically significant

$\left(\rho_{\text {int ercept }}=0,001, \rho_{z 1}=0,00036, \rho_{z 2}=0,025\right.$, respectively ) .

The multicollinearity of variables has been verified calculating the index of decreasing dispersion VIF. The value of both variables $V I F=1,367$ shows that the condition is satisfied.

Residents' awareness of heavy pollution in the residential environment is influenced by two indexes: distance to the city centre and density of streets. The longer is the distance 
to the city centre the lower is the level of air pollution and the higher is the density of streets the stronger the residents feel air pollution.

The accepted indexes:

1. Intention to move to another place to live (Y);

2. Feeling the noise generated by transport in the yard $\mathrm{X} 1$ ) - perceived indicator;

3. Heavy pollution in the residential environment (X2) perceived indicator;

4. Population density of the district, $\mathrm{p} / \mathrm{ha}(\mathrm{Z1})$ - measured indicator;

5. Traffic flow during the peak hour, (year 2000). (Z2) measured indicator;

6. distance to the city centre, km (V1) - measured indicator;

7. Density of streets, $\mathrm{km} / \mathrm{km}^{2}(\mathrm{~V} 2)$ - measured indicator.

\section{Application of Path Analysis for Evaluating Regression Models}

The produced regression models can be appropriatelly combined into a single network revealing causal relationships of the investigated variables. For this purpose, the applied method of path analysis allows simultaneous modelling of the relationship between a few interrelated regressions. Path analysis shows that one and the same variable can act as an independent variable in one type of relationship, and as a dependent - in the other. Moreover, this method graphically displays 'paths' the independent variables on which cause changes in dependent variables. Thus, path analysis facilitates the interpretation of the examined problem, and a graphical form of the path analysis model assists in a clearer understanding of the logic of conventional regression calculations and casual relationship. A general model of causal path analysis, including both regression equations (8 and 9) is presented in Fig. 5.

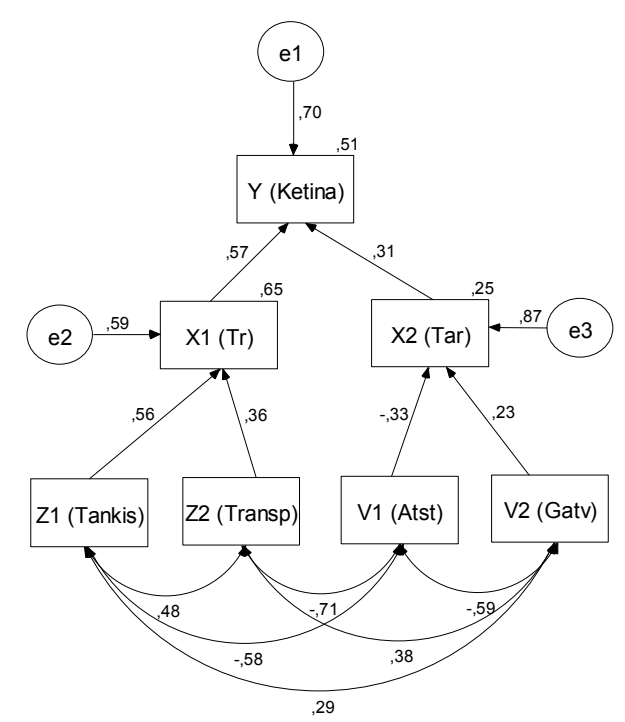

Figure 5. Casual model (path diagram) with path coefficients

Every variable has been transformed into a standard form, i.e. if variable $\mathrm{Vi}$ is measured, it can be transformed into form $V_{s}=\left(V_{i}-\bar{V}_{i}\right) / \delta_{V_{i}}$. The same condition applies for residuals e1, e2 and e3 accepted as a link to variables the behaviour of which can be explained employing the developed model. Tags near single-headed arrows are standardized regression weights. Tags near rectangles correspond to squared multiple correlation.

To verify model adequacy, model consistency indices, the majority of which are related to $\chi^{2}$ statistics, are applied. The hypothesis of model adequacy can be expressed as

1. $\mathrm{H}_{0}$ : the model is adequate for data, i.e. the matrices of variable covariance and model covariance are equal;

2. $\mathrm{H}_{1}$ : the model is not adequate for data, i.e. the matrices are not equal.

The calculation of meaning $p$ that is less than significance level $\alpha$ clearly indicates that the model is adequate for data.

The verification of the adequacy of the proposed model (Fig. 5) employing the selected method shows that the received value $\chi^{2}$ (Chi square) of the model equals 9.5, d.f. $=$ 9 , o $p=0,391$. Considering the general indexes of model adequacy, the obtained result is positive; to put it more precisely, the model is adequate when value $p$ is higher than 0,05 . Thus, a conclusion that the model is fully adequate for data can be made.

\section{Conclusions}

Literature analysis has revealed that not all countries and regions in Europe are at the same stage of urbanization cycle and the differences in urbanism in the European Union are increasing. Particularly the differences are felt in post-socialist countries. Under the influence of political changes and transformations many large cities in Eastern Europe in the last decade are confronted with decline in population, privatization patterns, deterioration, raised the land prices, lower life satisfaction then other Europe regions. This process has led to increased suburbanization and sprawl.

Lithuanian city suburbanization process had been analyzed by using driving forces of urban sprawl new paradigms (quality of life) identified in FOCI project results to approach a strategy or model to improve sustainable development perception in Lithuanian territorial planning.

In order to systemise the literature on drivers of urban sprawl the following dimensions have been considered: scale, demand and supply and domain. Quality of life is one of the main factors relevant at micro level. Macro level and meso level assessments are hiding spatial variation in quality of life that could prevail at micro level (periphery, district or city center). Moreover scientific research also reveals that the application of both indexes - objective and subjective is the most appropriate way of measuring the quality of life, whereas the obtained results can be applied for city planning.

To assess in the subjective position of Vilnius residents on the quality of life, reflecting index - a wish to move to 
another place to live now or in a few years' time - has been chosen and calculated taking into account every Vilnius district separately.

According to the numerical value of the index, the highest percentage of the population that expressed their opinion about changing their place of residence now or in a few years' time has been noticed in the districts located in the middle part of city functional structure.

Further research has disclosed that the index 'The intentions of Vilnius residents to move to another place to live now or in a few years' time' has been expressed in percent and has a statistically significant correlation with the indexes representing the group 'Environmental assessment of the districts and residential house'.

The method of correlation analysis and regression analysis has been applied for selecting subjective independent variables, including a subjective resident evaluation of the noise generated by transport in the yard and a subjective assessment of air pollution in the residential environment, to most reliably predict a dependent subjective variable (to move to another place to live).

The positive coefficients of the regression equation next to the variables have proved that the intention of the residents to move to another place to live is related to the noise generated by transport in the yard and heavy air pollution in the residential environment. Thus, the authors of the article agree that, in the case of higher numerical values of these indexes, the residents are more likely to move to other places of residence.

Moreover, the performed research demonstrates that understanding the noise generated by transport in the yard is influenced by two indexes: population density of the district and traffic flow during the peak hour. The higher are these indexes, the stronger the respondents are exposed to the noise generated by transport. Considering the assessment of the respondents exposed to noise in the districts, the highest percentage comes from middle part of city functional structure.

Residents' awareness of heavy air pollution in the residential environment is influenced by two indexes: distance to the city centre and density of streets. The longer is the distance to the city centre the lower is the level of air pollution and the higher is the density of streets the stronger the residents feel air pollution. Considering the assessment of the respondents exposed to air pollution in the districts, the highest percentage comes from the districts located in the middle part of city functional structure and the city centre.

On the basis of the conducted research, with reference to the used interval (normal) variables and without any intention to use more dependencies, the authors of the article have developed a few regression models. To combine the designed models, the paper employed path analysis. Taking into account the general indexes of model adequacy, the obtained verification results are positive. Thus, a conclusion that the model is adequate for data and dependencies can be made.

\section{References}

[1] M. Burinskienè, Subalansuota miestų plètra. Vilnius, Technika, 2003, pp. 58-62.

[2] B. Beham, S. Drobnic, R. Verwiebe, Literature Review. Theoretical Concepts and Methodological Approaches of Quality of Life and Work. Universiteit Utrecht and Universität Hamburg, 2006.

[3] B. Cavric, S. Toplek, A. Siljeg, Participatory measurements of sustainable urban development and quality of life in post socialist Zadar, Croatia, Spatium, 2008, 17 (18): pp. 45-54.

[4] R. Cowan, The Dictionary of urbanism, Streetwise Press, 2005, pp. 317.

[5] D. Das, Urban quality of life: A Case study of Guwahati, Social Indicators Research, 2008, 88(2): pp. 297-310.

[6] F. Dosch, Driving forces of land consumption in Germany, 2008, Available from Internet: http://www.bbr.bund.de/cln_005/nn_62854/EN/ResearchPro grammes/GeneralDepartmentalResearch/SpatialPlaning/Lan dConsumption/01_Start.html.

[7] ESPON Applied Research 2013, Future Orientations for Cities (FOCI), 2010, Available from Internet: http://www.espon.eu/export/sites/default/Documents/Project s/AppliedResearch/FOCI/FOCI_FinalReport_ScientificRep ort-r.pdf

[8] ESPON 2013 Publications. Available from Internet: http://www.espon.eu/main/Menu_Projects/

[9] ESPON 2006 Publications. Available from Internet: http://www.espon.eu/main/Menu_Publications/Menu_ESPO N2006Publications/

[10] T. S. Foo, Subjective assessment of Urban quality of life in Singapore (1997-1998), Habitat International, 2000, 24(1): pp. 31-49.

[11] R. W. Marans \& R. Stimson, An Overview of Quality of Urban Life. In Investigating Quality of Urban Life: Theory, Methods, and Empirical Research. Social Indicators Research Series, 2011, 45: pp. 1-33.

[12] R. McCrea, R. Stimson \& R. W. Marans, The Evolution of Integrative Approaches to the Analysis of Quality of Urban Life. In Investigating Quality of Urban Life: Theory, Methods, and Empirical Research. Social Indicators Research Series, 2011, 45: pp. 77-107.

[13] RAIT. Reprezentatyvi Vilniaus miesto gyventojų apklausa, 2005.

[14] A. Revi, M. Duble, Indicators for urban environmental services in Lucknow - process and methods, Environment and Urbanization, 1999, 11(3): pp. 227-245.

[15] N. Senlier, R. Yildiz \& E. Aktas, A perception survey for the evaluation of urban quality of life in Kocaeli and a comparison of the life satisfaction with the European Cities. Social Indicators Research, 2009, 94: pp. 213-226.

[16] D. Štreimikenè, A. Mikalauskienè, Integruotų rodikliu taikymas Nacionalinès energetikos strategijos monitoringui, Energetika, 2009, T. 55(3): pp.158-166. 
[17] E. S. Tesfazghi, J. A. Martinez \& J. J. Verplanke, Variability of quality of life at small scales: Addis Ababa, Kirkos sub-city. Social indicators research, 2010, 98(1): pp. 73-88.

[18] S. Wheeler, Planning for sustainability: creating livable, equitable, and ecological communities, United Kingdom, Routledge, 2004.
[19] S. G. Woldetinsaye, Analyzing variation of urban quality of life of life using using participatory approach in Addis Ababa, Ethiopia: a case study of Kirkos sub - city. University of Twente Faculty of Geo-Information and Earth Observation ITC, Enschede, 2011. 